\title{
In memoriam Jules Rippstein
}

\section{René Baumgartner}

Prof. em. Dr. med., Facharzt für Chirurgie, orthopädische Chirurgie und Traumatologie, Mitglied FMH

Der Basler Jules Rippstein gehört zur Generation Schweizer Orthopäden der Nachkriegszeit, deren Wirken national wie international Anerkennung gefunden hat.

Und wie bei den meisten seiner Kollegen erfolgte die Ausbildung zum Orthopäden bei Prof. M.R. Francillon an der damaligen Anstalt Balgrist in Zürich.

1957 wurde er Oberarzt am Hôpital Orthopédique de Lausanne unter Prof. Dr. med. Louis Nicod. Studienaufenthalte in Europa und den USA galten zwei Hauptthemen: Skoliose der Wirbelsäule und Amputationschirurgie und Prothesenversorgung.

\section{8 hat ihn die Deutsche Gesellschaft für Orthopädie und Traumatologie mit der Hohmann-Plakette gewürdigt.}

Vorbilder für ihn waren die interdisziplinären Kurse von Dr. Knud Jansen 1957-1962 am orthopädischen Spital Kopenhagen. Es ist das Verdienst von Dr. Rippstein, dieses Konzept in der Schweiz verwirklicht zu haben. Für Orthopäden, Orthopädietechniker und Physiotherapeuten veranstaltete er 1966 in Lausanne seinen ersten Cours de prothèses. Das war der Grundstein für die 1967 gegründete APO, die Schweizerische Arbeitsgemeinschaft für Prothesen und Orthesen. Ihre Besonderheit war nicht nur der interdisziplinäre Charakter, sondern auch die Mehrsprachigkeit deutsch/französisch. Ein Höhepunkt war das Ausrichten des 1. internationalen Kongresses der International Society for Prosthetics and Orthotics ISPO 1974 in Montreux mit über 1000 Teilnehmern.

1960-1976 betrieb Dr. Rippstein eine eigene orthopädische Praxis in Lausanne, um 1976-1986 als Kreisarzt zur SUVA zu wechseln.

1968 hat ihn die Deutsche Gesellschaft für Orthopädie und Traumatologie DGOT mit der Hohmann-Plakette gewürdigt, die Medizinische Fakultät Prag mit der Purkinje-Plakette, um nur die wichtigsten Auszeichnungen zu nennen.

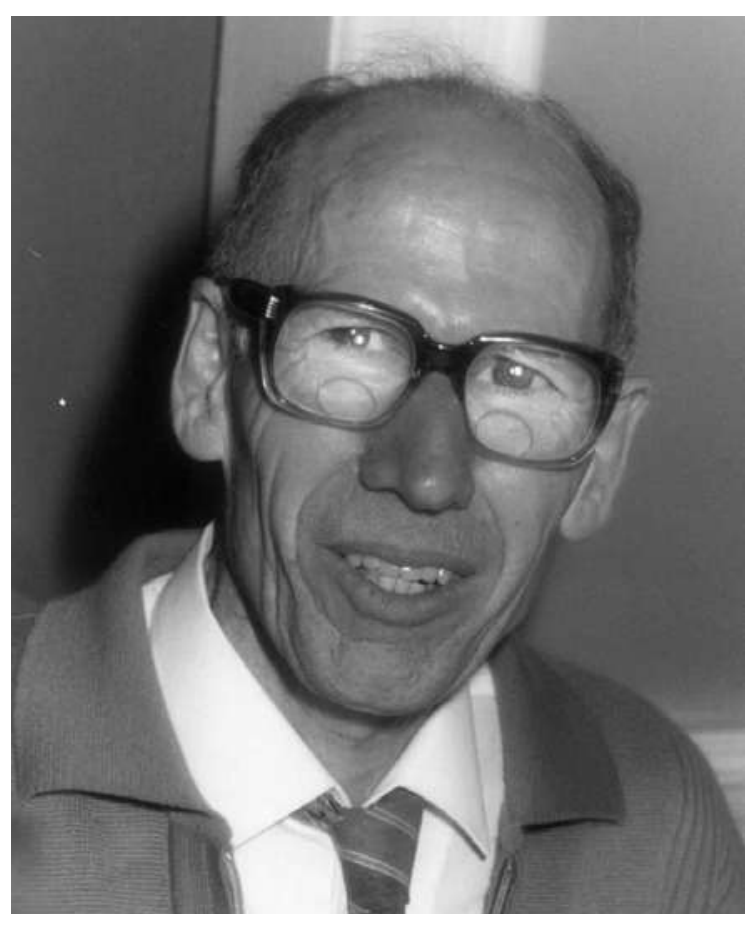

Dr. med. Jules Rippstein (1923-2016)

Das Erfinden und Sammeln orthopädischer Messinstrumente war seine Leidenschaft. Sein Hydro-Goniometer hat als Werbegeschenk der Fa. Geigy den Weg in alle Arztpraxen gefunden.

\section{Das Erfinden und Sammeln orthopädischer Messinstrumente war seine Leidenschaft.}

Dr. Rippstein erfand und sammelte Messgeräte in seiner Garage, die er als feinmechanische Werkstatt eingerichtet hatte. René Ruepp und René Baumgartner haben seine orthopädischen Messgeräte in einer eigenen Schrift veröffentlicht.

Das Bild von Jules Rippstein wäre unvollständig ohne seinen legendären Sinn für Humor. Selbst als ihm ein Augenleiden schwer zu schaffen machte, konnte er herzlich lachen über die Welt und sich selbst. 